\title{
The transversal flow microfiltration module. Theory, design, realization and experiments*
}

\author{
F N M Knops, H Futselaar and I G Rácz \\ Unuverstty of Tuente, Dept of Chemucal Engineering, $P O B \circ \times 217,7500$ AE Enschede (The Netherlands)
}

(Received July 16, 1991, accepted in revised form April 6, 1992)

\begin{abstract}
This study shows that the permeate flux in microfiltration can be increased without increasing energy consumption, by using the hollow fiber membranes themselves as turbulence promoters This is realized by using shell-side fed hollow fibers, which are placed perpendicular to the feed stream This module type is called the transversal flow module The theoretical benefits of such a module have been calculated by applying the model proposed by Zydney and Colton to predict the permeate flux Furthermore the technical realization of a module with a filtering area of $05 \mathrm{~m}^{2}$ as well as the first preliminary microfiltration results will be discussed

Keywords microfiltration, module design, concentration polarization, turbulence promotion, transversal flow
\end{abstract}

\section{Introduction}

In membrane filtration in general and in crossflow microfiltration especially a severe flux decline in the permeate flow can appear When operating an installation with a very fouling feed stream, containing e $g$ yeast, the flux can drop to $1 \%$ of the clean water flux For other kınds of pressure driven membrane processes the flux can vary from $50 \%$ for reverse osmosis to $10 \%$ for ultrafiltration So especially for $\mathrm{ml}^{-}$ crofiltration it can be useful to control and to decrease this flux decline

Correspondence to I G Rácz, University of Twente, Dept of Chemical Engineerıng, P O Box 217, 7500 AE Enschede (The Netherlands)

*Paper presented at the Int Symp on "Progress in Membrane Science and Technology", Enschede, Netherlands, June 25-28, 1991
Flux decline can be caused by several factors, e g concentration-polarization, adsorption, gellayer formation and plugging of the pores [1] All these factors can be considered as a resistance against transport of a permeate from a feed solution across a membrane ( $\left.F_{1} g 1\right)$

The plugging resistance $\left(R_{\mathrm{p}}\right)$ depends on the particle dimensions and on the pore dimen-

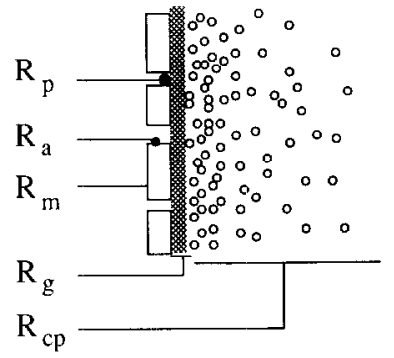

$R_{p}$ pore-blocking

$R_{a}$ adsorption

$R_{m}$ membrane

$R_{g}$ gel layer formation

$\mathbf{R}_{\mathrm{cp}}$ concentration polarization

Fig 1 Sketch of a membrane with various resistances 
sions The adsorption resistance $\left(R_{\mathrm{a}}\right)$ depends on the properties of the particle material and the membrane material. The membrane resistance $\left(R_{\mathrm{m}}\right)$ is a function of the pore radius, the porosity and the turtuosity The gellayer resistance $\left(R_{\mathrm{g}}\right)$ and the concentration-polarization resistance $\left(R_{\mathrm{cp}}\right)$ depend on the composition of the feed stream, the process conditions and the module performance

This work deals with reducing the resistance due to concentration polarization $\left(R_{\mathrm{cp}}\right)$ by changing the module geometry, under the assumption that no gel-layer is formed $\left(R_{\mathrm{g}}=0\right)$

\section{Theory}

Various models are used to predict the permeate flux in crossflow microfiltration Examples are: the models of Schock [2], of Blake [3] and of Schultz and Ripperger [4] The models of Schock and Blake describe the permeate flux by using the force balance on a single particle in the feed stream. The model of Schultz and Ripperger uses the pressure drop across the membrane to calculate the permeate flux These models do not predict the permeate flux in relation to concentration-polarization.

The model proposed by Zydney and Colton [5] describes the permeate flux by using the concentration-polarization model. It extends the existing models with describing the influence of particle diffusion near the membrane wall At steady state, the boundary layer is in a dynamic equilıbrium If it is approximated by a stagnant film, the rate of convection of particles normal to the membrane is balance by diffusion back into the bulk

$J(x) C=D \frac{\mathrm{d} C}{\mathrm{~d} y}$

where $J(x)$ is the local permeate flux in the flow direction, $C$ the particle concentration, $D$ the particle diffusion coefficient, and $y$ the distance to the membrane This expression is in- tegrated over the boundary layer thickness $\delta(x)$ to give:

$J(x)=\frac{D}{\delta(x)} \ln \frac{C_{\mathrm{w}}}{C_{\mathrm{b}}}=k(x) \ln \left(\frac{C_{\mathrm{w}}}{C_{\mathrm{b}}}\right)$

where $k(x)$ is the local mass transfer coefficient, $C_{\mathrm{w}}$ the particle concentration near the membrane wall and $C_{\mathrm{b}}$ the particle concentration in the bulk. According to Zydney and Colton for microfiltration the local mass transfer coefficient can be described as

$k(x)=0538\left(\frac{D^{2} \bar{\gamma}}{x}\right)^{1 / 3}$

where $x$ is the axial coordinate along the channel and $\bar{\gamma}$ is the average wall shear rate at the surface of the channel. Integration of the local mass transfer coefficient along the length of the channel yields an expression for the length-averaged flux

$J=\frac{1}{L} \int_{0}^{L} J(x) \mathrm{d} x=0.807\left(\frac{D^{2} \bar{\gamma}}{L}\right)^{1 / 3} \ln \left(\frac{C_{\mathrm{w}}}{C_{\mathrm{b}}}\right)$

The effective diffusivity, arısing from partıcle migrations and rotations, governs particle transport in crossflow microfiltration This diffusivity increases with the square of the particle radius $(a)$ and linearly with the shear rate Above a particle concentration of $20 \%$ it is constant with a value of

$D=003 a^{2} \bar{\gamma}$

If eqn (5) is incorporated in eqn (4) the length-averaged flux is given as

$J=0078\left(\frac{a^{4}}{L}\right)^{1 / 3} \bar{\gamma} \ln \left(\frac{C_{\mathrm{w}}}{C_{\mathrm{b}}}\right)$

So the permeate flux $J$ is a function of:

- particle radius $a$

- particle concentration near the wall $C_{\mathrm{w}}$

- particle concentration in the bulk $C_{\mathrm{b}}$ 
- channel length $L$.

- average shear rate $\bar{\gamma}$.

The theory of Zydney and Colton has some limitations:

- It can only predict the maximum pressureindependent permeate flux

- It does not predict the flux decline in time

- It assumes the particle concentration in the feed stream to be constant along the module This only applies for a high feed flow.

However, according to eqn (6) the permeate flow can be enhanced by.

- Changing the feed stream: enlarging the particle radius or decreasing the particle concentration.

- Enlarging the shear rate.

- Reducing the channel length

Some remarks on these topics*

- Changing the feed stream is rather impractical in most applications. Only in very special applicatıons particle radius can be increased by flocculation [5].

- The shear rate can be enlarged by increasing the pressure drop over the module.

$\bar{\gamma}=\frac{\Delta P_{\text {mod }} A_{\mathrm{d}}}{\eta A_{\mathrm{w}}}$

The shear rate is a function of the pressure drop over the module $\left(\Delta P_{\text {mod }}\right)$, the area of the cross-section $\left(A_{\mathrm{d}}\right)$, the wetted area of the module $\left(A_{\mathrm{w}}\right)$ and of the feed stream viscosity ( $\eta$ ) The pressure drop depends on the feed flow velocity and on the module desıgn. A higher pressure drop over the module can be realized by enlarging the feed flow $(\Phi)$ (by using recirculation) Increasing both the feed flow and pressure drop implies the energy consumption $(W)$ to increase linearly to the pressure drop and to the feed flow.

$W=\Delta P_{\bmod } \Phi$

A better way to increase the permeate flux is to increase the pressure drop over the module

while maintaining a low feed flow velocity, 1 e by changing the module design.

- A short channel length means decreasing the length along which a boundary layer is buildup This can be done in two ways reducing the module length or changing the module design An example: most membrane manufacturers buld longitudinal modules with a length of approximately $10 \mathrm{~m}$ By using two modules of $0.5 \mathrm{~m}$ instead of one module of 10 $\mathrm{m}$ the permeate flow should increase $26 \%$, according to the theory of Zydney and Colton.

$J_{05}=\left(\frac{1}{0.5}\right)^{1 / 3} J_{1}=126 J_{1}$

In this work we have modified the module design Hollow fiber membrane modules can be of a tube-side fed type or a shell-side fed type The shell-sıde fed module can be operated in longitudinal flow (feed flow along the fiber) or in transversal flow (feed flow perpendicular to the fiber) A schematic drawing of a transversal flow module is presented in Fig 2.

The basic principle of a transversal flow module is well known and was investigated by Yang and Cussler [6], Akzo international research [7], Rhône-Poulenc [8], Standard Oıl [9]

The transversal design has basically the same benefits as the corrugated-plate membrane modules, which were realized by Van der Waal et al. [10,11]. In this modules, turbulence is increased by the corrugations, resulting in high values of mass transfer, especially in the region

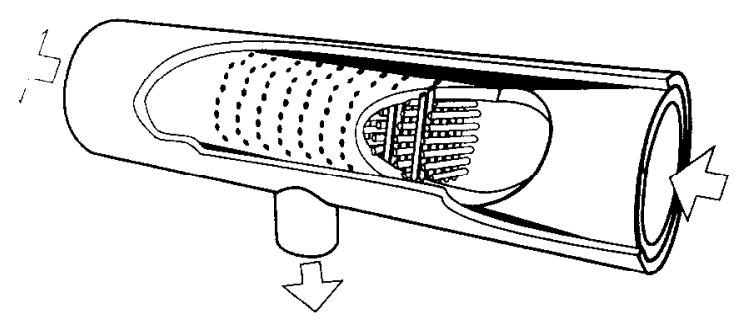

Fig 2 Sketch of a transversal flow microfiltration module 
of reattachment of the streamlines (Fig. 3).

The expected theoretical benefits of the transversal flow module can be calculated according to eqn (6) The permeate flux $J$ is a function of known parameters

- The particle radius

- The concentration

- The channel length and of unknown parameters

- 'The particle concentration near the membrane wall

- The average shear rate

Zydney and Colton estimated the concentration $C_{\mathrm{w}}$ for rigid particles to be $74 \%$, assuming a hexagonal close-packing The average shear rate depends on the pressure drop across the module and on the module dimensions (eqn 7) For longitudinal flow modules the pressure drop across the module can be calculated using

$\Delta P_{\bmod }=\xi \frac{L}{d_{1}} \frac{\rho v^{2}}{2}$

The friction factor $\xi$ is a function of the Reynolds number [12] Brauer [13] derived an equation to predict the pressure drop over transversal flow heat exchangers

$\Delta P_{\text {mod }}=\frac{N}{2} \xi_{\mathrm{t}} \frac{\pi^{3} R e_{\mathrm{h}}^{2}}{16} \frac{\rho \nu^{2}}{d^{2}} \frac{1}{\left(\frac{s_{\mathrm{t}}}{d}-\frac{\pi}{4}\right)^{3}}$

where $N$ is the number of grids, 1.e. the number of hollow fibers placed after each other in the module, $R e_{\mathrm{h}}$ is a function of the mean velocity and of the hydraulic diameter $d_{\mathrm{h}}$, the friction factor is a function of the Reynolds number and of the relation $s_{t} / d, \nu$ is the kinematic viscosity of the feed stream

The module type to compare the transversal flow module with, is a tube-side fed longitudinal flow module This module is produced by $\mathrm{X}$-Flow [14] Equation (6) is solved for a range of Reynolds numbers for these two module types The solution used for the calculations is a suspension of $05 \%$ (by volume) rigid particles. The particle diameter is $05 \mu \mathrm{m}$

$X$-Flow R05-PVC

$\begin{array}{ll}\text { Membrane area } & A_{\text {mem }}=05 \mathrm{~m}^{2} \\ \text { Module length } & L=05 \mathrm{~m} \\ \text { Internal fiber diameter } & d_{1}=155 \mathrm{~mm} \\ \text { Number of fibers } & 250\end{array}$

Transversal flow module, yet to produce

$\begin{array}{lll}\text { Membrane area } & A_{\text {mem }}=0474 \mathrm{~m}^{2} \\ \text { Module length } & L & =021 \mathrm{~m} \\ \text { Outer fiber diameter } & d & =21 \mathrm{~mm} \\ \text { Internal module diameter: } & 62 \mathrm{~mm} \\ \text { Number of grids } & N=100 \\ \text { Transversal pitch } & s_{\mathrm{t}}=42 \mathrm{~mm}\end{array}$

Both modules have the same microfiltration fibers poly-ether sulfon with a pore diameter of $02 \mu \mathrm{m}$ produced by X-Flow

According to the theory of Zydney and Colton the modules have the same performance for low Reynolds numbers (Fig 4), and with increasing Reynolds number the permeate flux of a transversal flow module increases much more than the flux of a longitudinal flow module

Although the transversal flow module shows

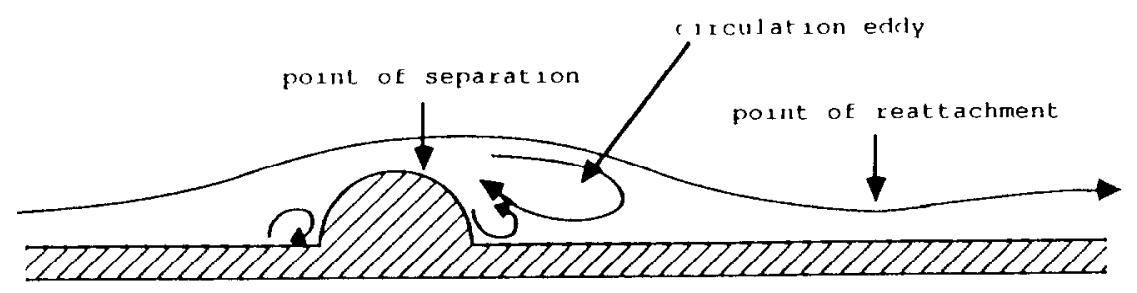

Fig 3 Impression of streamlines for flow over corrugated plates 


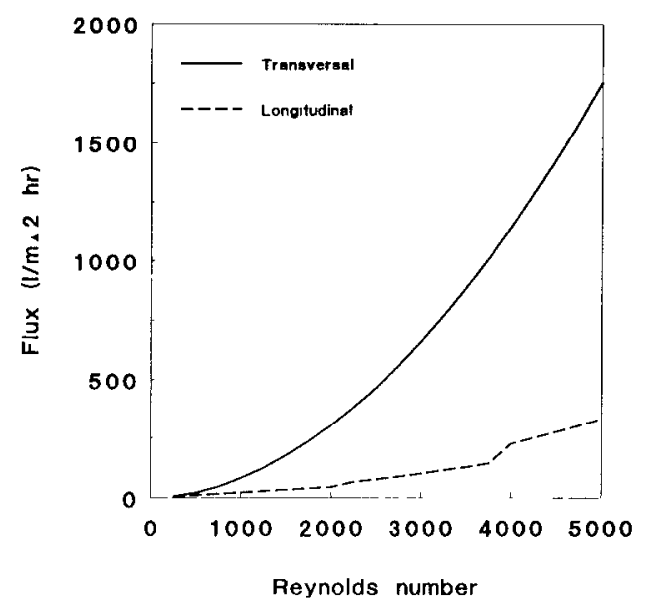

Fig 4 Calculated flux as a function of Reynolds number for transversal flow and longitudinal flow modules

a better performance than the longitudinal flow module, this is not convincing to potential industrial customers. These data have to be translated to costs In general there are two groups of costs

- the investment costs

- the operating costs

Investment costs are linear to the number of square meters of membrane area required to produce one cubic meter of permeate per hour.

$A_{\mathrm{sp}}=\frac{1}{J}$

The operating costs are represented by the specific power consumption, 1.e. the power consumption per cubic meter of permeate

$W_{\mathrm{sp}}=\frac{\Phi \Delta P_{\mathrm{mod}}}{A_{\mathrm{mem}} J}$

Both factors, specific membrane area as well as specific power consumption are functions of the Reynolds number (F1g 5). The specific membrane area decreases and the specific power consumption increases with increasing Reynolds number This implicates that increasing the membrane area (so investment costs) will decrease the power consumption (so the oper-

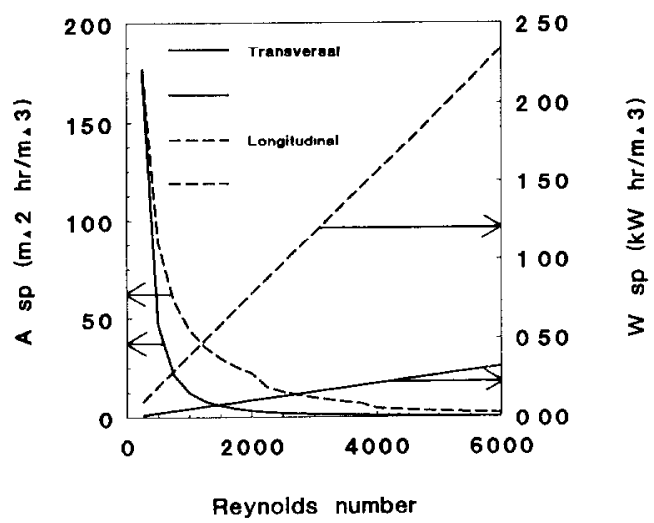

Fig 5 Calculations of specific membrane area and specific power consumption as a function of Reynolds number for transversal flow and longitudinal flow modules

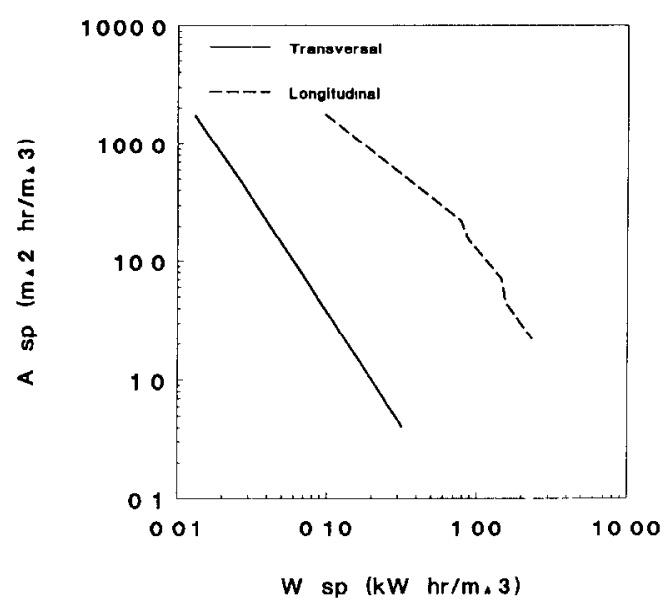

Fig 6 Calculations of specific power consumption versus specific membrane area for transversal flow and longitudinal flow modules

ating costs). Combining the two lines results in a graph displaying the energy consumption versus the specific membrane area (Fig. 6 ). An operating point at the bottom left means less total costs for a given membrane area. Moving to the right and upwards means increasing total costs Because of both axis being logarithmic this graph can only be used in a qualitative way, that is to compare the modules At this point we can conclude it could be profitable to use transversal flow modules instead of longitudinal flow modules 


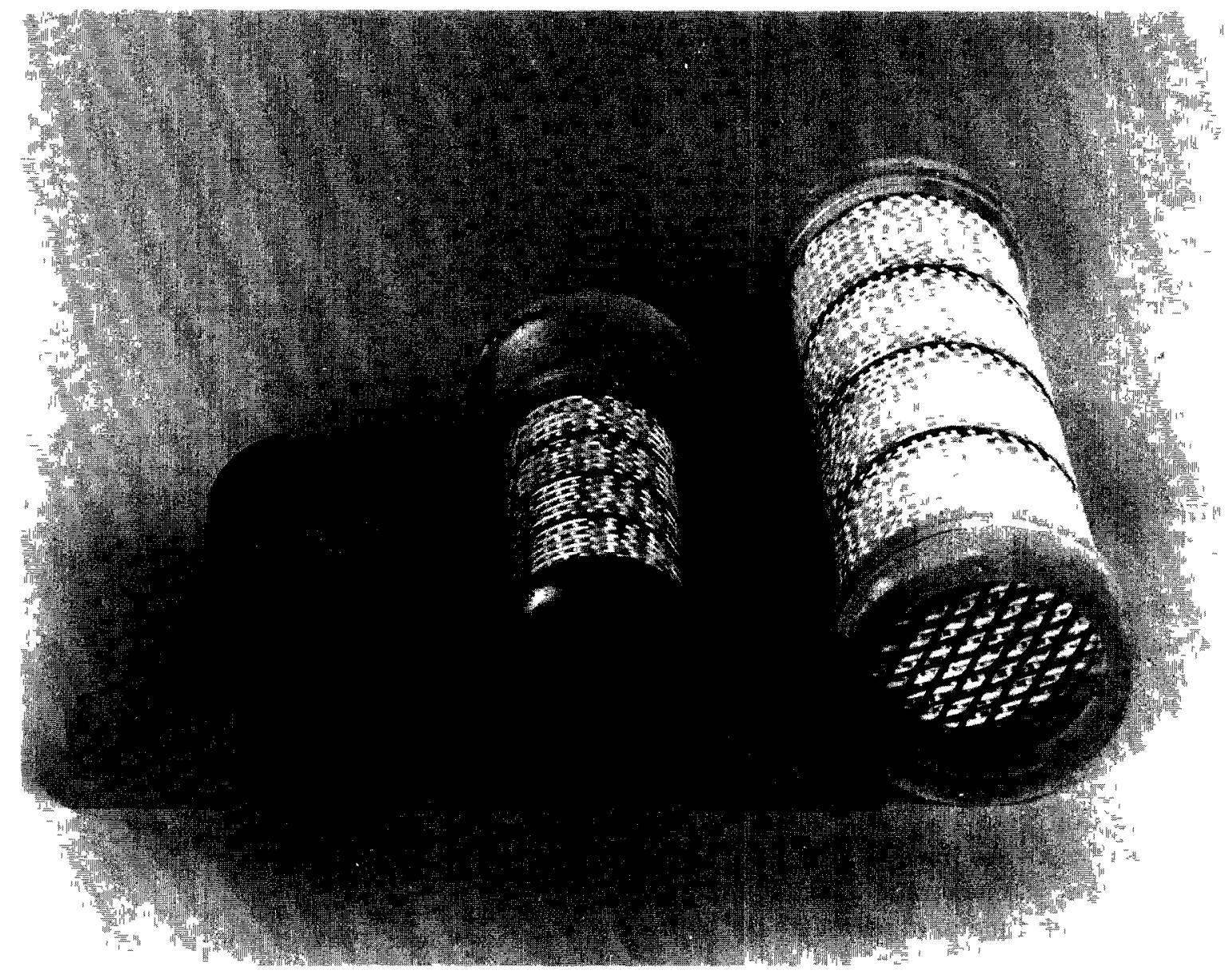

Fig 7 Photograph of series of realızed transversal flow modules

\section{Transversal modules}

A photograph showing a chronological order of module series realızed is shown in Fig. 7 The production technique is a centrifugal casting technique similar to the technique described by Nichols [9]

\section{Experiments}

The experimental set-up was a closed loop circulation system, controlling the operating pressure, the feed flow velocity and the temper- ature (Fig 8) The maximum feed flow is $8 \mathrm{~m}^{3} / \mathrm{hr}$ and the maximum operating pressure 1s $4.5 \times 10^{5} \mathrm{~Pa}$ A personal computer is used to record the measured operating pressure, the pressure drop over the module, the feed flow velocity and the permeate flux

The experiments have been carried out with polystyrene globules This is a monodisperse material which has no interactions with the membrane material The partıcle diameter is $05 \mu \mathrm{m}$ and the bulk concentration is $0.5 \%$ (by volume) The results are given in Table 1 . These values are the average of 5 experiments each and are recalculated to the specific power con- 


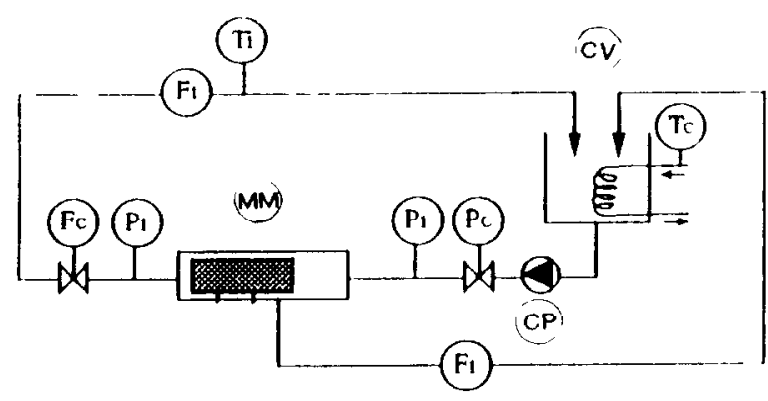

Fig 8 Flowdiagram of experimental set-up CV circulation vessel, $\mathrm{CP}$ circulation pump, $\mathrm{MM}$ membrane module, $\mathrm{Pc}$ pressure control valve, $\mathrm{P}_{1}$ pressure indicator, $\mathrm{Fc}$ flow control valve, $\mathrm{F}_{1}$ flow indicator, $\mathrm{T}_{1}$ temperature indicator, Tc temperature control

\section{TABLE 1}

Comparison of longitudinal flow and transversal flow modules in microfiltration of $05 \mathrm{vol} \%$ later globules

\begin{tabular}{|c|c|c|c|c|c|}
\hline$R e$ & $\begin{array}{l}\Phi \\
\left(\mathrm{m}^{3} / \mathrm{hr}\right)\end{array}$ & $\begin{array}{c}\Delta P_{\bmod } \\
\left(\times 10^{5}\right. \\
\mathrm{Pa})\end{array}$ & $\begin{array}{l}\text { Permeate } \\
\text { flux } \\
\left(\mathrm{l} / \mathrm{m}^{2}-\mathrm{hr}\right)\end{array}$ & $\begin{array}{l}A_{\mathrm{sp}} \\
\left(\mathrm{m}^{2}-\mathrm{hr}\right. \\
\left.\quad / \mathrm{m}^{3}\right)\end{array}$ & $\begin{array}{l}W_{\mathrm{sp}} \\
(\mathrm{kW}-\mathrm{hr} \\
\left./ \mathrm{m}^{3}\right)\end{array}$ \\
\hline \multicolumn{6}{|c|}{ Longitudinal flow module } \\
\hline 2400 & 40 & 067 & 211 & 474 & 0706 \\
\hline 3100 & 50 & 083 & 216 & 463 & 1067 \\
\hline 3700 & 60 & 135 & 204 & 490 & 2206 \\
\hline \multicolumn{6}{|c|}{ Transversal flow module } \\
\hline 1500 & 30 & 007 & 295 & 339 & 0042 \\
\hline 2200 & 45 & 015 & 440 & 227 & 0090 \\
\hline 2400 & 50 & 017 & 430 & 233 & 0116 \\
\hline
\end{tabular}

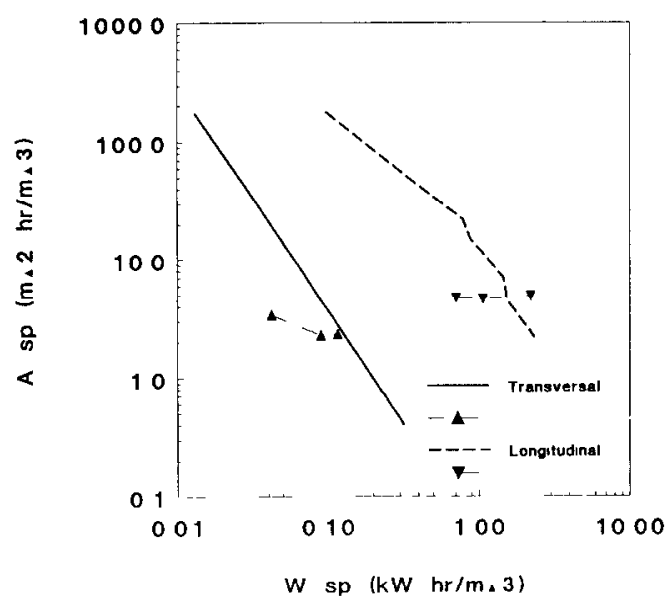

Fig 9 Comparison of experimental values on calculations sumption and to the required membrane area and plotted in Fig 9

\section{Discussion}

The recorded data of the transversal flow module fit nicely to the predictions The longitudinal flow module is better than predicted. The reason for this effect can be that the boundary layer which is build up from the entrance of the module is limited to a maximum. This maximum is related to the internal radius of the hollow fiber Beyond the point at which this maximum is reached the rest of the module has a boundary layer with a constant height. The theory of Zydney and Colton predicts the boundary layer to increase all along the module to a very high value at the rear end of the module

Because of the effect of a limited boundary layer height the cutting in two pieces of a longitudinal flow module will result in a smaller increase in permeate flux than predicted by the theory

The experiments have been reconfirmed with experiments carried out with a $2 \%$ (by weight) yeast concentration (particle diameter approx $6 \mu \mathrm{m})$

Reynolds Permeate flux Permeate flux number Longitudinal flow Transversal flow

$4600 \quad 27 \mathrm{l} / \mathrm{m}^{2}-\mathrm{hr} \quad 51 \mathrm{l} / \mathrm{m}^{2}-\mathrm{hr}$

Probably because of a gel-layer formation and because of particle adsorption it is not possible to fit these values to the theory

Further research will be extended to other testing materials, like pigments and emulgated oll, commonly used in the industry Another 
point of research will be optimizing the process conditions. The effects of temperature and of backflushing will be investigated

\section{Conclusions}

(1) It is possible to produce transversal flow microfiltration modules in series by using a centrifugal casting technique developed in our laboratory.

(2) There is an overall fair agreement between the experimental data and the permeate flux predictions of the model proposed by Zydney and Colton

(3) Transversal flow microfiltration modules require less membrane area and/or less energy consumption than longitudinal flow modules to produce a given amount of permeate

\section{Acknowledgements}

These investigations were supported by the Dutch Foundation for Technical Sciences (STW) and by X-Flow B V Almelo J Koopmans cooperated in order to fullfil the requirements for his $M$ Sc. thesis $M$ Janssen and $R$ Holtkamp, both B Sc.-students, also contributed to this research.

\section{List of symbols}

a particle radius (m)

$A_{\mathrm{d}} \quad$ area of the cross-section $\left(\mathrm{m}^{2}\right)$

$A_{\text {mem }}$ membrane area $\left(\mathrm{m}^{2}\right)$

$A_{\mathrm{sp}} \quad$ specific membrane area $\left(\mathrm{m}^{2}-\mathrm{sec} / \mathrm{m}^{3}\right)$

$A_{\mathrm{w}} \quad$ wetted area of a module $\left(\mathrm{m}^{2}\right)$

$C$ particle concentration (-)

$C_{\mathrm{b}} \quad$ particle concentration in the bulk (\%)

$C_{\mathrm{w}} \quad$ particle concentration near the wall

(\%)

$D \quad$ particle diffusion coefficient $\left(\mathrm{m}^{2} / \mathrm{sec}\right)$

$d \quad$ outer fiber diameter $(\mathrm{m})$

$d_{\mathrm{h}} \quad$ hydraulic diameter $(\mathrm{m})$

$d_{1} \quad$ inner fiber diameter $(\mathrm{m})$
$J$ permeate flux $\left(\mathrm{m}^{3} / \mathrm{m}^{2}-\mathrm{sec}\right)$

$J(x) \quad$ local permeate flux $(\mathrm{m} / \mathrm{sec})$

$k(x)$ local mass transfer coefficient $(\mathrm{m} /$

sec)

$L \quad$ channel length ( $\mathrm{m})$

$N \quad$ number of grids in a transversal module $(-)$

$R e_{\mathrm{h}} \quad$ hydraulic Reynolds number (-)

$s_{\mathrm{t}} \quad$ transversal pitch $(\mathrm{m})$

$W$ power consumption (W)

$W_{\mathrm{sp}} \quad$ specific power consumption (W-sec/ $\mathrm{m}^{3}$ )

$x \quad$ axial coordinate (m)

$y$ distance to the membrane $(\mathrm{m})$

Greek

$\bar{\gamma} \quad$ average shear rate $(1 /$ sec $)$

$\delta(x) \quad$ local boundary layer thickness (m)

$\Delta P_{\text {mod }}$ pressure drop over the module $(\mathrm{Pa})$

$\eta \quad$ dynamic viscosity $(\mathrm{Pa}-\mathrm{sec})$

$\nu \quad$ kinematic viscosity $\left(\mathrm{m}^{2} / \mathrm{sec}\right)$

$\xi \quad$ friction factor (-)

$\xi_{t} \quad$ transversal friction factor (-)

$\rho \quad$ gravity $\left(\mathrm{kg} / \mathrm{m}^{3}\right)$

$\Phi$ feed flow $\left(\mathrm{m}^{3} / \mathrm{sec}\right)$

\section{References}

1 M H V Mulder, Basıc Principles of Membrane Technology, Kluwer Academic Publishers, Dordrecht, 1991, Chap 8, p 282

2 G Schock, Mikrofiltration an uberstromten Membranen, Ph D Thesis, Aachen, 1985

3 N J Blake, I W Cumming and M Streat, Prediction of steady state crossflow filtration using a force balance model, Proc Vth World Filtration Congress, Nice, France, June 5-8, 1990, pp 579-585

4 G Schulz and S Ripperger, Concentration polarization in crossflow microfiltration, J Membrane Sc1, 40 (1989) 173-187

5 A L Zydney and C K Colton, A concentration polarization model for the filtrate flux in crossflow microfiltration of particle suspensions, Chem Eng Commun, 47 (1986) 1-21

6 M C Yang and E L Cussler, Designing hollow fiber contactors, AIChE J , 32 (11) (1986) 1910-1916 
7 H Stam, Membrane separation of $\mathrm{CO}_{2}$ and $\mathrm{H}_{2} \mathrm{~S}$ from mixtures with gaseous hydrocarbons, in L Cecille and J -C Toussaint (Eds ), Future Industrial Prospects of Membrane Processes, Proc Symp on Basic Research in Industrial Technologies, Brussels, Belgium, Dec 6-7, 1988, Elsevier Applied Science, London, 1988, pp 135-152

8 J Baudet, M Rochet, M Salmon and B Vogt, Hollow fiber assembly for use in fluid treatment apparatus, U S Patent 3,993,816 (1976)

9 R W Nichols, Hollow fiber separation module and method for the use thereof, US Patent 4,959,152 (1990)

10 M J Van der Waal and I G Rácz, Mass transfer in corrugated-plate membrane modules I Hyperfiltra- tıon experıments, J Membrane Scı , 40 (1989) 243260

11 M J Van der Waal, S Stevanovic and I G Rácz, Mass transfer in corrugated-plate modules II Ultrafiltration experiments, J Membrane Sc1, 40 (1989) 261275

12 VDI-Warmeatlas, 5 Auflage, VDI-Verlag, Dusseldorf, 1988, pp Lb1-7

13 H Brauer, Stromuungswiderstand und Warmeubergang be1 quer angestromten Warmeaustauschern mit kreuzgitterformig angeordneten Glatten und berppten Rohren, Chemie Ing Techn, 36 (3) (1964) 247260

14 X-Flow B V, Technical Documentation R 05-PVC (1991) 